International Research Journal of Management, IT \& Social Sciences
Available online at https://sloap.org/journals/index.php/irjmis/
Vol. 7 No. 2, March 2020, pages: 1-8
ISSN: 2395-7492
https://doi.org/10.21744/irjmis.v7n2.852

\title{
Rubrics Implementation on Learning Evaluation for Superior Basic Students
}

\author{
Geomara Karinel Patiño Briones ${ }^{\text {a }}$ \\ David Alejandro Navarrete Solórzano ${ }^{\text {b }}$ \\ Erwin Alejandro Villamil Moreira ${ }^{c}$
}

Article history:

Submitted: 09 November 2019

Revised: 18 December 2019

Accepted: 27 January 2020

\section{Keywords:}

evaluation process;

learning;

methodology of rubrics;

rubrics;

teaching;

\begin{abstract}
This research aims to analyze the implementation of rubrics in the Evaluation of learning in the students of higher basic of the Educational Unit "June $5 \mathrm{~N}^{\circ}$ 34 ", 2019. With a sampling strategy of probabilistic type, a survey of teachers of the upper basic level of the areas of Language and Literature has conducted Natural Sciences, Social Studies, Mathematics, Physical Education, Cultural and Artistic Education and English with results that favor stating the problem that has evidenced by the weak use of rubrics in the processes of learning evaluation. From the surveys, it has been concluded that the teaching professionals have the knowledge of this evaluation instrument and its singularities but that the overvaluation of systematic tests as a measuring instrument is part of the evaluation processes rooted in the conduct of these professionals who Do not open to innovation. From the researchers 'perspective, the methodology in the use of rubrics has to be implemented in classrooms to give real value to the evaluation of students' knowledge.
\end{abstract}

International research journal of management, IT and social sciences (C) 2020. This is an open access article under the CC BY-NC-ND license (https://creativecommons.org/licenses/by-nc-nd/4.0/).

\section{Corresponding author:}

Geomara Karinel Patiño Briones,

Master's Student of the Pontificia Universidad Católica Del Ecuador, Sede Manabí, Portoviejo.

Email address: gpatino3543@pucem.edu.ec

\footnotetext{
a Pontificia Universidad Católica Del Ecuador, Sede Manabí, Portoviejo

${ }^{\mathrm{b}}$ Pontificia Universidad Católica Del Ecuador, Sede Manabí, Portoviejo

Pontificia Universidad Católica Del Ecuador, Sede Manabí, Portoviejo
} 


\section{Introduction}

Within the evaluation process of education, evaluation patterns have created that have used for a long time and remain effective for Know the scope of the knowledge that students have acquired. Engaging in new learning trends proposes a series of effective tools that can be applied individually and in groups to assess knowledge effectively. The rubric as an evaluation tool that has not been valued in its magnitude of possibilities that it provides to the educational process not only for the teacher. Who can be done with a magnificent instrument that can generate real grades, but also serves as a guiding guide for students who through these can know how their homework should be, know what the teacher expects from his performance as a student.

\section{Materials and Methods}

This research is located within the non-experimental quantitative methods. Specifically, it is a descriptive survey-type study, of an exploratory nature, carried out with a questionnaire that has applied to 15 teachers of the Educational Unit "June $5 \mathrm{~N}^{\circ} 34$ " of the Canuto-Chone Parish, province of Manabí.

\section{Results and Discussions}

\subsection{Definition of the rubric construct}

First, knowledge of the rubric construct is a concept that has not been in vogue for many decades, On the other hand, teachers often know it as an evaluation instrument or a way to evaluate, but much is still unknown on the subject. The rubrics have considered as a product or resource that is born from the exhaustive work of professionals committed to professional excellence. Also considered, as instruments that it favors making known the requirements of the professional evaluator with a view to the quality and improvement of his professional work (Alcón \& Menéndez, 2015). When used at the time of the evaluation, rubrics to evaluate means a maximum degree of utility, which provides helps and makes the evaluation process in teaching and learning feasible. Emphasizing expected objectives in academic performance and student learning, if this document or instrument is accessible to students and has socialized by the mediator or facilitator (Alcón \& Menéndez, 2015).

In figure 1, the "Rubric" construct has defined as an instrument for the support of the evaluation of students of higher basic.

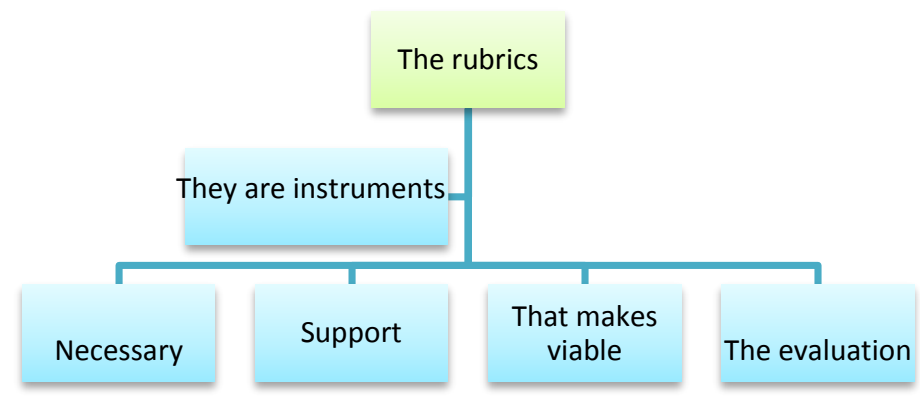

Figure 1. Definition of the rubric construct

Source: (Alcón \& Menéndez, 2015)

3.2 Methodology in the use of rubrics

Design of rubrics

When making a rubric, it has usually thought that it is a complicated job or an impossible mission, but when it is clear about the essential aspects, the type of rubric and the advantages, its design becomes possible. These instruments have more cavity and acceptance by teachers who seek an authentic evaluation of palpable and measurable performance 
(Andrade \& Atorresi, 2010). Its elaboration conceives clear objectives, elements to be valued, descriptors, evaluation and to reflect its educational contribution (Gatica \& Uribarren, 2012).

The aspects to have considered in the elaboration of a rubric according to Carrioza \& Gallardo (2013), are detailed in Figure 2.

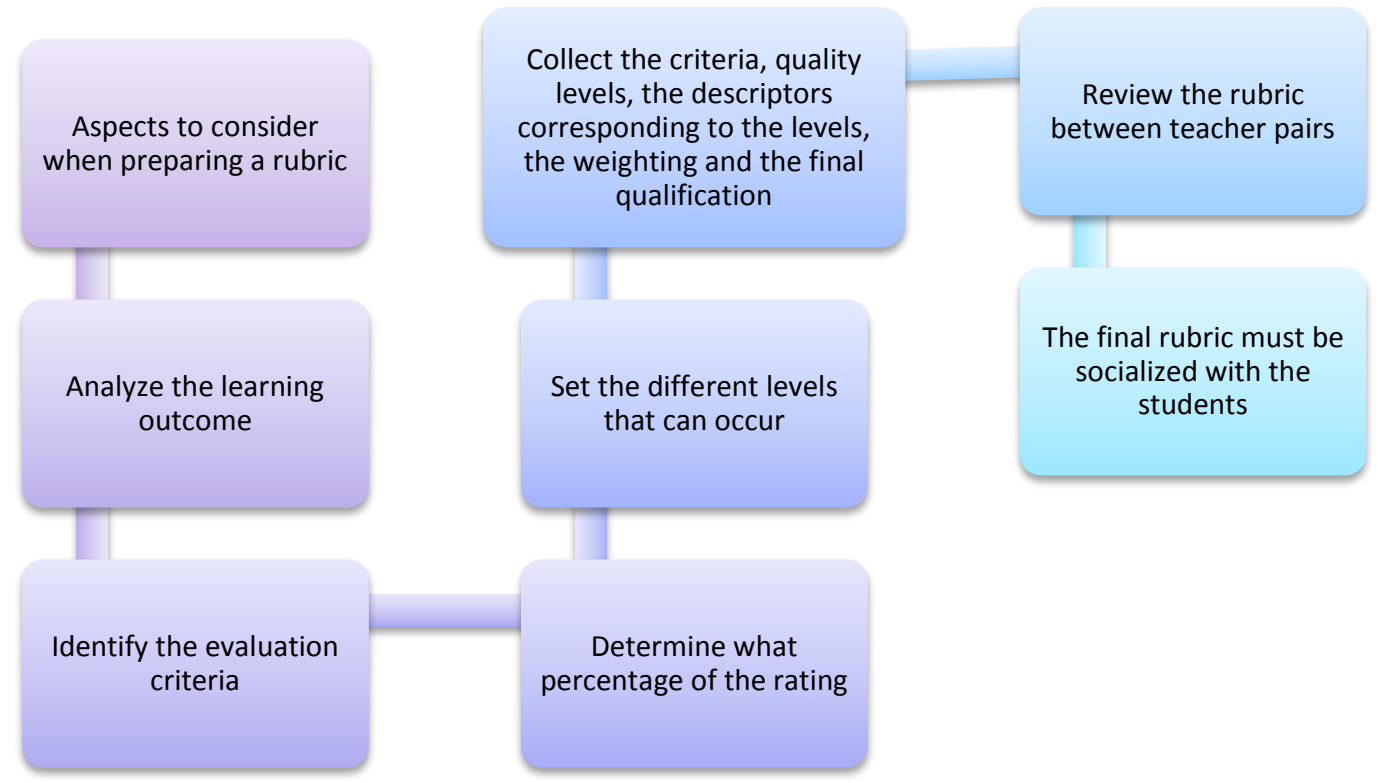

Figure 2. Aspects to consider in the elaboration of a rubric Source: (Carrioza \& Gallardo, 2013)

In reality, the recommendations provided provide a general form of processes to arrive at the construction and design of a rubric. With regard to structural design, a rubric has reflected in a double-entry table; the rows correspond to the evaluation criteria and the columns to the performance levels. This instrument establishes the task is its components and establishes what is acceptable or not in each of its aspects descriptively. The vertical column corresponds to the quality dimension and the aspects to have evaluated; the rows express the domain levels, and the cells represent the criteria used when measuring the selected aspects. In other examples, the scheme may vary, but they all have quality levels and criteria (Cebrian \& Monedero, 2009). So that through the rubrics you can analyze and identify the aspects in which students have to strengthen; what aspects have related to the final grade or other aspects of the students (Morales, 2011). It also emphasizes the pedagogical actions around the procedures and not so much the result or final product (Jorba \& Sanmartí, 1993).

Table 1 shows in detail what has studied, which shows the concepts, the levels of competence and the evidence obtained.

Table 1

Detail of the studied

\begin{tabular}{|c|c|c|}
\hline Concepts & Levels & Evidence \\
\hline $\begin{array}{l}\text { General and Specific. } \\
\text { Technical Professionals } \\
\text { Of meanings, acts, and morals. } \\
\text { Of all kinds. }\end{array}$ & $\begin{array}{l}\text { Very high } \\
\text { Level of competition High level of } \\
\text { competition. } \\
\text { The average level of competition. } \\
\text { Very low level of competition. }\end{array}$ & $\begin{array}{l}\text { Essays, papers, written reports, } \\
\text { debates, portfolios, question } \\
\text { techniques, projects, case methods, } \\
\text { laboratory work ... demonstrating: } \\
\text { Cognitive skills } \\
\text { Adaptation to the environment } \\
\text { Technological and linguistic skills, } \\
\text { oral and written communication. } \\
\text { ICT management } \\
\text { Problem-solving }\end{array}$ \\
\hline
\end{tabular}

Briones, G. K. P., Solórzano, D. A. N., \& Moreira, E. A. V. Rubrics implementation on learning evaluation for superior basic students. International Research Journal of Management, IT and Social Sciences, 7(2), 1-8. https://doi.org/10.21744/irjmis.v7n2.852 


\begin{tabular}{|c|c|c|c|}
\hline & & & $\begin{array}{l}\text { Critical and self-critical } \\
\text { skills Social skills } \\
\text { Integration of understanding } \\
\text { Sensitivity and knowledge. } \\
\text { Research and creativity. }\end{array}$ \\
\hline
\end{tabular}

Source: (Villalustre, 2010)

There is a pleasure on the part of the student body to know the aspects it has considered and generate more confidence than to ignore those (Gallego \& Raposo, 2014). According to the most known type or classification that allows us to use according to the rubrics are holistic and analytical. The first for a primary level and the second for a basic level towards a higher level (Cáceres \& Fernández, 2011). In table 2, the characteristics of holistic and analytical rubrics have shown.

Table 2

Characteristics of holistic and analytic rubrics

\begin{tabular}{ll}
\hline \multicolumn{1}{c}{ Rubricsholistic } & Rubricsanalytical \\
\hline Apply when: & Apply when you value: \\
Consider mistakes in the process without & Different aspects of the process and the product. \\
affecting the quality of the task. & Look for feedback to a high degree in each criterion. \\
Its design requires a minimum of time. & Establishes diagnostic profiles at the individual and \\
You need a more summative than formative & group levels. \\
evaluation. & Set different weights for the components.
\end{tabular}
Source: (Cáceres \& Fernández, 2011)

Considering the above, the feedback is achievable through an analytical rubric, which has more applied by teachers for a more thorough evaluation. On the other hand, holistic rubrics have designed to measure skills in certain tasks (Mueller, 2012).

The advantages are sufficient for its application regarding the importance and its relevance. These instruments constitute an innovation that has not yet applied, despite has known, its validity has crystallized in an authentic and realistic evaluation with a comprehensive and thorough vision at the same time (Martínez, 2008). In short, the rubrics as an instrument provide us with a real and authentic evaluation of the educational work in the classroom. Figure 3 addresses the advantages of rubrics, according to (Mertler, 2001).
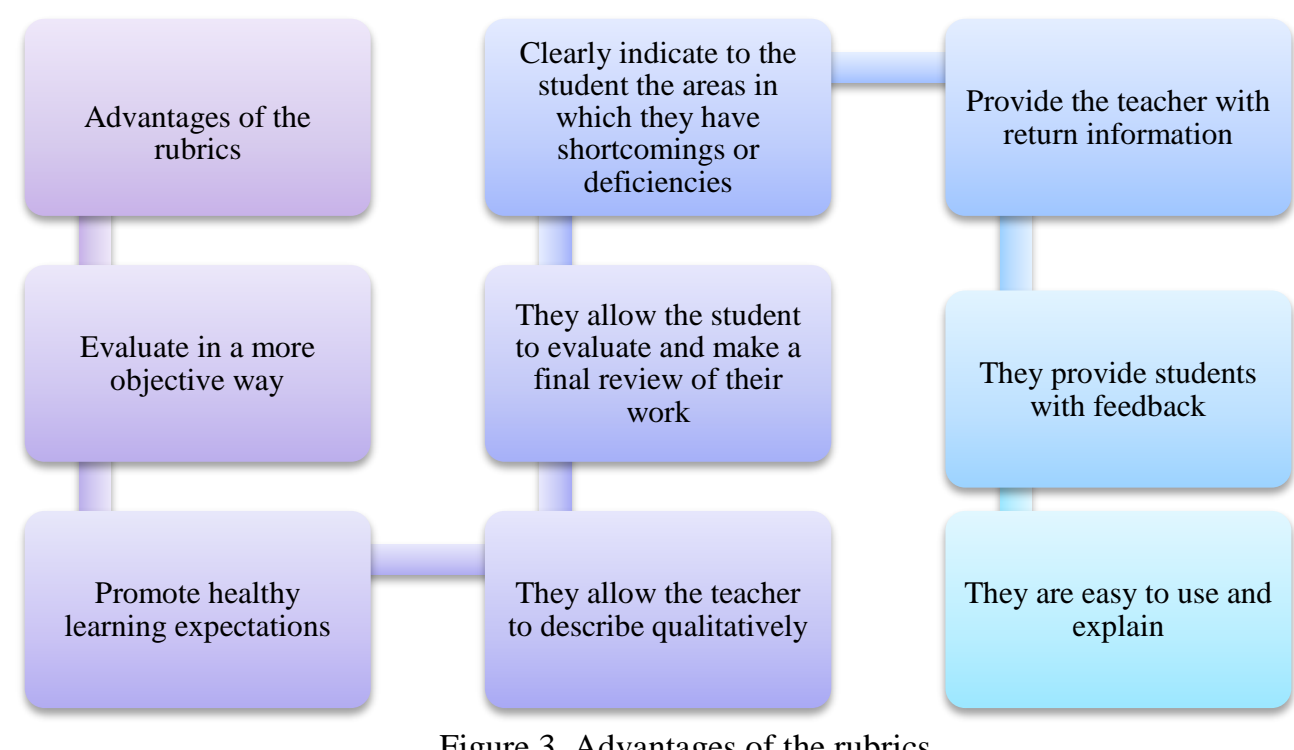

Figure 3. Advantages of the rubrics Source: (Mertler, 2001) 


\subsection{Authentic Evaluation}

Also known as an action-based evaluation, it has applied through activities that demonstrate the knowledge that the student has acquired and can demonstrate (Morrison, 2004; Tuarez, 2019), this author also states that if the learning they are not significant, they have considered has not authentic.

The authentic evaluation according to Zaitegui et al. (2012), has based on the following pillars:

a) It is an evaluation that trains, trains the student and trains the teacher as a member of the education system.

b) It is formative, so it must be continuous.

c) Its purpose seeks to improve educational processes when it is still on time.

d) It is demonstrative, renewed, specific, contextualized, qualitative, representative and transferable.

e) Within what fits, it is ethical. The evaluation criteria must be public.

f) It has a direct relationship with the contents.

g) It has shown at various levels of difficulty to assess learning diversity.

h) It is not exclusively testable.

i) It has not used as a corrective instrument.

j) It does not serve to measure.

\subsection{Advantages of Authentic Evaluation}

Among the advantages of authentic evaluation according to (Vallejo \& Molina, 2014): It

a) Allows to confront learning It

b) Allows to show and share models of as work of experiences It

c) leads to give transparency and to seek consensus between the parties

d) As an evaluation: it gives varied opportunities to document what has learned and look for options to improve student performance. Students and teachers

e) Expands opportunities in the curriculum and the possibility of supervising, self-assessing and perfecting one's work.

f) It provokes the self-regulation of student learning. It

g) Provides real feedback on both students and teachers. It

h) Empowers students to act and self-assess.

The questionnaire was given to teachers of the Basic Superior, with a detailed explanation of the same, the objective and importance of their opinions. After being collected, we proceeded to tabulation and analysis. The following figures show the results obtained. Figure 4 shows the evaluation instruments considered in the educational process.

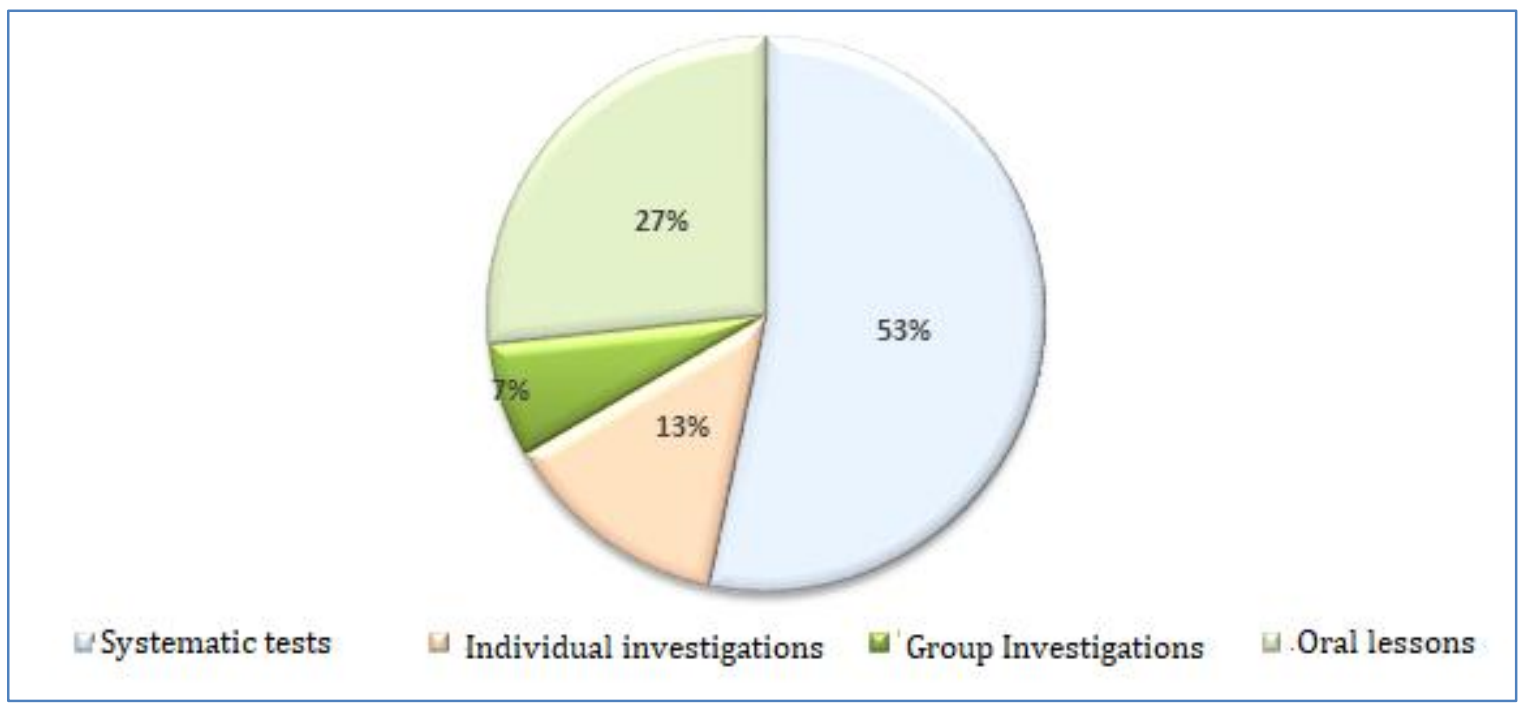

Figure 4. Assessment instruments considered in the evaluation process

Briones, G. K. P., Solórzano, D. A. N., \& Moreira, E. A. V. Rubrics implementation on learning evaluation for superior basic students. International Research Journal of Management, IT and Social Sciences, 7(2), 1-8. https://doi.org/10.21744/irjmis.v7n2.852 
The $53 \%$ of teachers put faith in systematic tests to evaluate learning. The latter understood as "something that can be observed and documented ... which reflects the acquisition of knowledge or skills" (Garcia et al., 2015) and 27\% of teachers consider oral lessons as suitable; another 13\% show their approval of individual investigations and finally, $7 \%$ rely on group investigations. Figure 5 shows the aspects that are not fully evaluated in-class days.

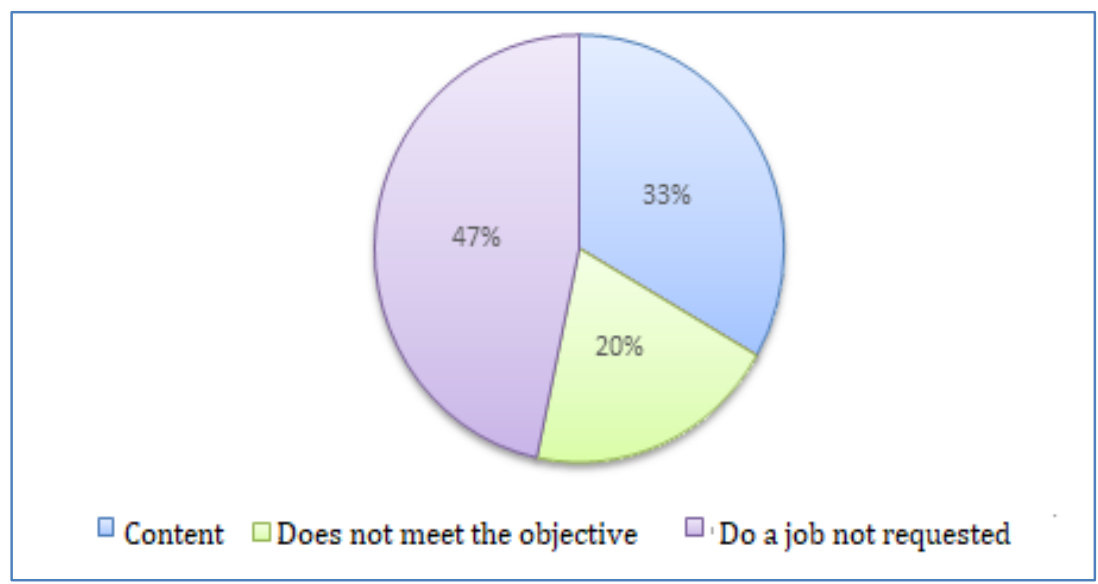

Figure 5. Aspects that have not evaluated in their entirety

Relating to the question of the aspect that escapes when evaluating, participants in a point out that it is the procedural aspect with $60 \%$; there is an inconsistency with the process applied with unexpected results. According to Ramos (2016), in order for the evaluation criteria to fulfill their formative function; it is necessary to have sequenced reference points from the beginning of the process. For this, teachers must distribute the criteria of each cycle sequentially in the courses that compose it. In addition, the evaluation process has been carried out to have an excellent process of analyzing the results obtained. The graph of figure 6 shows the needs of the students when presenting any work.

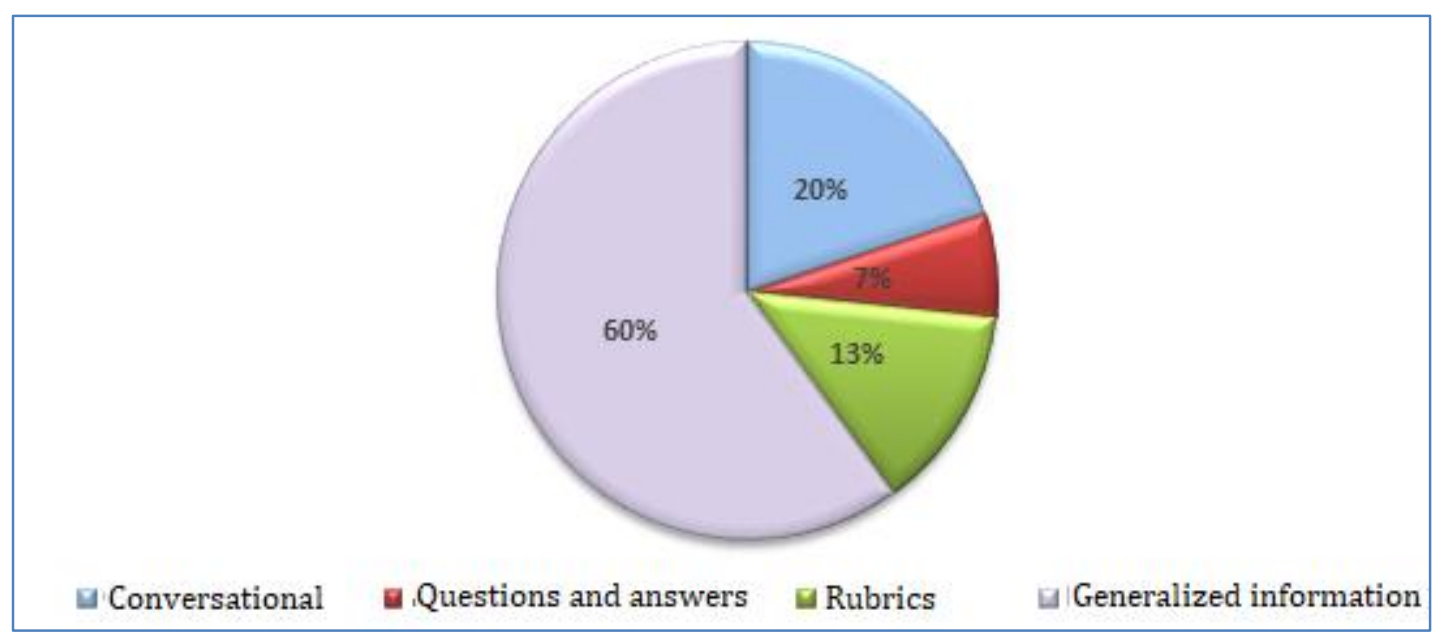

Figure 6. Resources used to publicize the aspects to has evaluated

When asked how to know the aspects to be evaluated, 13\% manifest through rubrics. "A rubric is an instrument that translates complex visions of expected performance into specifications that can be understood by agents not experts in the teaching profession" (Alcón \& Menéndez, 2015; Vera, 2019). In other words, an instrument enables the understanding of the aspects to have evaluated that the student must develop. By noting the low percentage of use of rubrics, it is possible to understand why students do not reach the effective development of a task, fulfill unsolicited aspects and do not achieve the objective desired by the education professional.

In contrast, "the rubrics emphasize and describe the expected objectives in learning, thus facilitating effective academic performance; as long as this instrument is publicly accessible to the students and socialized to them" (Alcón 
\& Menéndez, 2015), but despite this, only $13 \%$ trust their usefulness as an evaluation tool. Andrade \& Atorresi (2010), affirm that "the rubrics are increasingly accepted by educators who are moving towards more authentic and performance-based evaluations", in opposition to the aforementioned only $13 \%$ of teachers know this instrument and it has not known background of its use in practice. Although there are already designed rubrics on the web that could be applied without developing the same teacher (Alcón \& Menéndez, 2015). The last question of the survey asks for an opinion, which was considered to be of little importance, so it does not show the use of the evaluation instrument, the object of the investigation. In summary, we can feel that although the rubrics have been in use for decades and their knowledge and application are relative and subjective for participating teachers, they have not realized that it represents the solution to more effectively assess student learning.

\section{Conclusion}

The rubrics are effective evaluation instruments to make students aware of the aspects to have evaluated. The socialization of the same makes possible the achievement of the expected objectives in any entrusted activity or task; objectivity and impartiality prevailing; not giving cavity to speculations and subjectivities. The dissatisfaction of the teacher, before a poorly developed academic work, by a student, who does not meet the objectives, set and not deeply socialized, is a constant void in the evaluation process of the teachers participating in the research. Teachers who overvalue systematic tests as reliable instruments that cover the entire evaluation process.

\section{Conflict of interest statement}

The authors declared that they have no competing interests.

Statement of authorship

The authors have a responsibility for the conception and design of the study. The authors have approved the final article.

\section{Acknowledgments}

We are grateful to two anonymous reviewers for their valuable comments on the earlier version of this paper.

Briones, G. K. P., Solórzano, D. A. N., \& Moreira, E. A. V. Rubrics implementation on learning evaluation for superior basic students. International Research Journal of Management, IT and Social Sciences, 7(2), 1-8. 


\section{References}

Alcon Latorre, M., \& Menendez Varela, J. L. (2015). The contribution of rubrics to authentic assessment practice. OBSERVAR, 9, 5-17.

Andrade, H., \& Atorresi, A. (2010). Understanding the rubrics. Enunciation, 15 (1), 161-167.

Cáceres, P., \& Fernández, A. (2011). The use of rubrics to improve the quality criteria in the evaluation.

Carrioza, E., \& Gallardo, J. (2013). Rubrics for guidance and evaluation in virtual learning environments (PhD thesis). Open University of Catalonia, Barcelona, Spain.

Cebrian, M., \& Monedero, J. (2009). The e-portfolio and the e-rubric in the supervision of the practicum. (Undergraduate thesis). University of Malaga, Malaga, Spain.

Gallego, M., \& Raposo, M. (2014). Student commitment and perception of the evaluation process based on rubrics. University Teaching Magazine, 12 (1), 197-215.

Garcia, F., Fonseca, G., \& Concha, L. (2015). Learning and academic performance in higher education. Research in education news, 1-26.

Gatica, F., \& Uribarren, T. (2012). How to make a rubric? Research in Medical Education, 2(1), 61-65.

Jorba, J., \& Sanmartí, N. (1993). The rubrics in the pedagogical actions. Classroom of Educational Innovation, 8(10), 34-40.

Martínez, J. (2008). The rubrics in the school evaluation: its construction and its use. Advances in Measurement, 6(12), $129-138$.

Mertler, A. (2001). Obtained from Designing scoring rubrics for your classroom. Practical Assessment, Research \& Evaluation, 7(25), 1-8.

Morales, P. (2011). Written works, correction and evaluation.

Morrison, G. (2004). Infant Education Madrid, Spain: Pearson Ediucation.

Mueller, J. (2012). Obtained from Rubrics: http://jfmueller.faculty.noctrl.edu/toolbox/rubrics.htm

Ramos, A. (2016). Body of Teachers Primary education. Temary. Vol. I. Madrid, Spain: CEP EDITORIAL.

Tuarez, M. A. V., Delgado, M. A. C., Delgado, R. I. Z., \& Romero, J. E. V. (2019). Approaches to evaluation assumed by teachers on teaching process - learning. International Journal of Social Sciences and Humanities, 3(3), 60-70. https://doi.org/10.29332/ijssh.v3n3.361

Vallejo, M., \& Molina, J. (2014). The Authentic Evaluation of Educational Processes. Iberoamericana (64), 11-25. doi: https://rieoei.org/historico/documentos/rie64a01.pdf

Vera, A. B. G., Vera, M. K. G., Garcia, A. M. R., \& Miranda, M. J. V. (2019). Application of self-evaluation and coevaluation on learning processes. International Journal of Linguistics, Literature and Culture, 5(5), 7-14. https://doi.org/10.21744/ijllc.v5n5.727

Villalustre, L. (2010). E-portfolio and evaluation rubrics on ruralnet. Pixel-Bit Media and education magazine, 6(37), 93-105.

Zaitegui, N., Ávila, M., Castillo, I., \& Cantón, I. (2012). He evaluated it as a systematic process for educational improvement. Madrid, Spain: Ministry of Education. 